\title{
PENGEMBANGAN PERANGKAT PEMBELAJARAN DI PAUD GEMILANG
}

\section{Yuki Widiasari}

PGPAUD FKIP Universitas Muhammadiyah Purwokerto

\begin{abstract}
Early childhood education curriculum must be appropriated with children character and the rule of government. This year every early childhood education use 2013's curriculum. In PAUD Gemilang this curriculum applied too. Based on accreditation advise the institution have a problem in device learning because still applied the curriculum in a part of learning activity. The problem like: daily lesson plan and scientific evaluation. So, we improve device learning in order to appropriate.
\end{abstract}

Keywords: device learning, early childhood education

\begin{abstract}
Abstrak
Kurikulum pendidikan anak usia dini harus disesuaikan dengan karakter anak dan peraturan pemerintah. Tahun ini setiap pendidikan anak usia dini menggunakan kurikulum tahun 2013. Di PAUD Gemilang kurikulum ini juga diterapkan. Terdapat beberapa masalah seperti rencana pembelajaran dan evaluasi berbasis saintifik. Kegiatan ini berusaha untuk memberikan pendampingan dalam penyusunan perangkat pembelajaran agar sesuai dengan tuntutan kurikulum.
\end{abstract}

Katakunci: perangkat pembelajaran, pendidikan anak usia dini

\section{PENDAHULUAN}

Kurikulum 2013 Pendidikan Anak Usia Dini (PAUD) sudah mulai dilaksanakan di beberapa lembaga PAUD. Dasar pelaksanaannya adalah PP No. 32 Tahun 2013 tentang perubahan Standar Nasional Pendidikan merupakan salah satu dasar perubahan kurikulum dalam Pendidikan Anak Usia Dini. Kurikulum PAUD sejak dulu sudah terpadu sehingga perubahan kurikulum ini 
bukanlah sesuatu yang kontras hanya penyenpurnaan pola pikir seperti bagan di bawah ini:
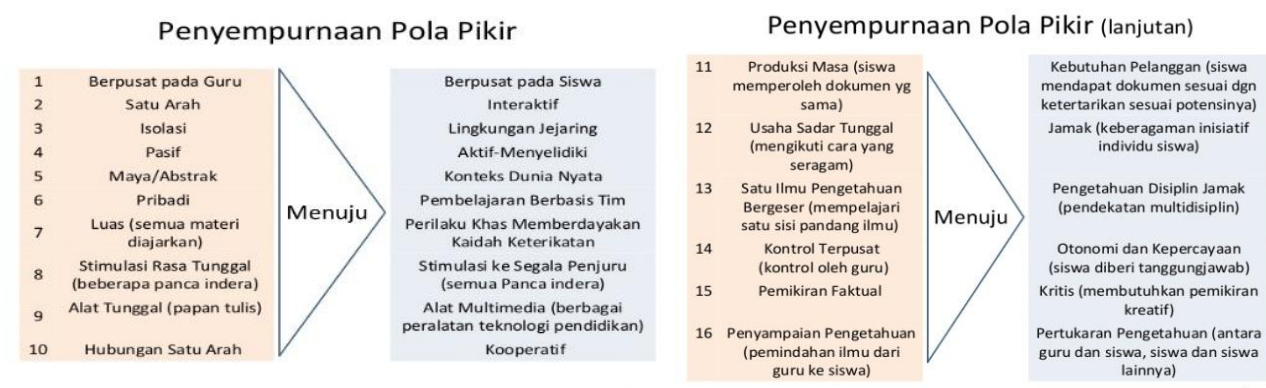

Lembaga pendidikan anak usia dini (PAUD) saat ini lebih mudah ditemui di sekitar kita baik yang formal maupun non formal. Hal ini menunjukkan meningkatkan kesadaran berbagai pihak terhadap masa golden age yang membutuhkan stimulasi, salah satunya melalui pendidikan anak usia dini. Tersedianya PAUD yang mudah diakses memungkinkan masyarakat memilih PAUD yang terbaik dan sesuai dengan karakter putra putrinya. PAUD yang ada pun harus memenuhi persyaratan penyelenggaraan yang sudah diatur dalam Permen No. 58 tahun 2009. Standar PAUD tersebut tercantum dalam Permen 58 Tahun 2009 Pasal 1 meliputi (1) tingkat pencapaian perkembangan, (2) pendidik dan tenaga kependidikan, (3) isi, proses, dan penilaian, dan (4) sarana prasarana, pengelolaan, dan pembiayaan.

Berdasarkan standar PAUD di atas maka PAUD Gemilang Kembaran sebagai salah satu lembaga PAUD juga sudah melaksanakan kurikulum 2013 PAUD yang ditunjukkan pada perangkat pembelajaran yang sesuai dengan kurikulum 2013. Di tahun ini PAUD Gemilang mengajukan akreditasi dan sudah divisitasi, hasil penilaian akreditasinya adalah B. Beberapa masukan dari tim penilai adalah masih belum tersedianya perangkat pembelajaran yang sesuai dengan kurikulum 2013. Perangkat pembelajaran yang perlu perbaikan antara lain: program semester, RPPM, RPPH, media pembelajaran, dan penilaian 
pembelajaran. Oleh karena itu PAUD Gemilang Kembaran hendaknya mulai melakukan pembenahan dan penyesuaian agar pelaksanaan pembelajaran sesuai dengan kurikulum 2013 yang berlaku.

Berdasarkan hal di atas permasalahan PAUD Gemilang Kembaran adalah penyusunan perangkat pembelajaran yang terdiri dari:

1. Guru masih mengalami kesulitan menyusun perencanaan pembelajaran yang sesuai dengan kurikulum 2013 PAUD,

2. Guru belum memahami materi ajar yang harus dipersiapkan dalam kegiatan pembelajaran,

3. Guru kebingungan untuk memenuhi kelengkapan media pembelajaran, dan

4. Guru belum memahami sistem penilaian dengan cara yang benar.

\section{PEMBAHASAN}

\section{Kurikulum}

Kurikulum merupakan suatu program kegiatan terencana, memiliki rentang yang cukup luas, hingga membentuk suatu pandangan yang menyeluruh (Saylor, Alexander, dan Lewis, 1968). Kurikulum memiliki tiga peranan (Hamalik, 2009) yaitu:

a. peranan konservatif yaitu kurikulum memiliki tanggung jawab mentransmisikan dan menafsirkan warisan sosial pada generasi muda.

b. peranan kritis yaitu turut aktif berpartisipasi dalam kontrol sosial dan memberi penekanan pada unsur berpikir kritis.

c. peranan kreatif yaitu kurikulum berperan dalam melakukan berbagai kegiatan kreatif dan konstruktif.

Di samping memiliki peranan, kurikulum juga memiliki fungsi. Alexander Inglis (1918) mengemukakan bahwa kurikulum berfungsi antara 
lain: fungsi penyesuaian, fungsi pengintegrasian, fungsi diferensiasi, fungsi persiapan, fungsi pemilihan, dan fungsi diagnostik.

\section{Pendekatan Saintifik dalam Pembelajaran}

Berpikir saintifik adalah Kemampuan berpikir dalam memahami masalah, menganalisa, mencari pemecahannya, dan menghasilkan sesuatu yang inovatif dan kreatif (Kuhn \& Pearsall, 2000; Kuhn dan Schauble, \& Garcia-Milla, 1992). Lepper (dalam Nugraha, 2008) pengembangan pembelajaran sains mencakup 4 kompetensi inti yaitu KI 1 : Sikap Spiritual; KI 2 : Sikap Sosial; KI 3 : Pengetahuan; KI 4 : Keterampilan. Pendekatan saintifik adalah pendekatan pembelajaran yang memberikan kesempatan kepada anak untuk mendapat pengalaman belajar melalui mengamati, menanya, mengumpulkan informasi, menalar, dan mengkomunikasikan (Permendikbud No. 81 A Tahun 2013) seperti bagan di bawah ini: 


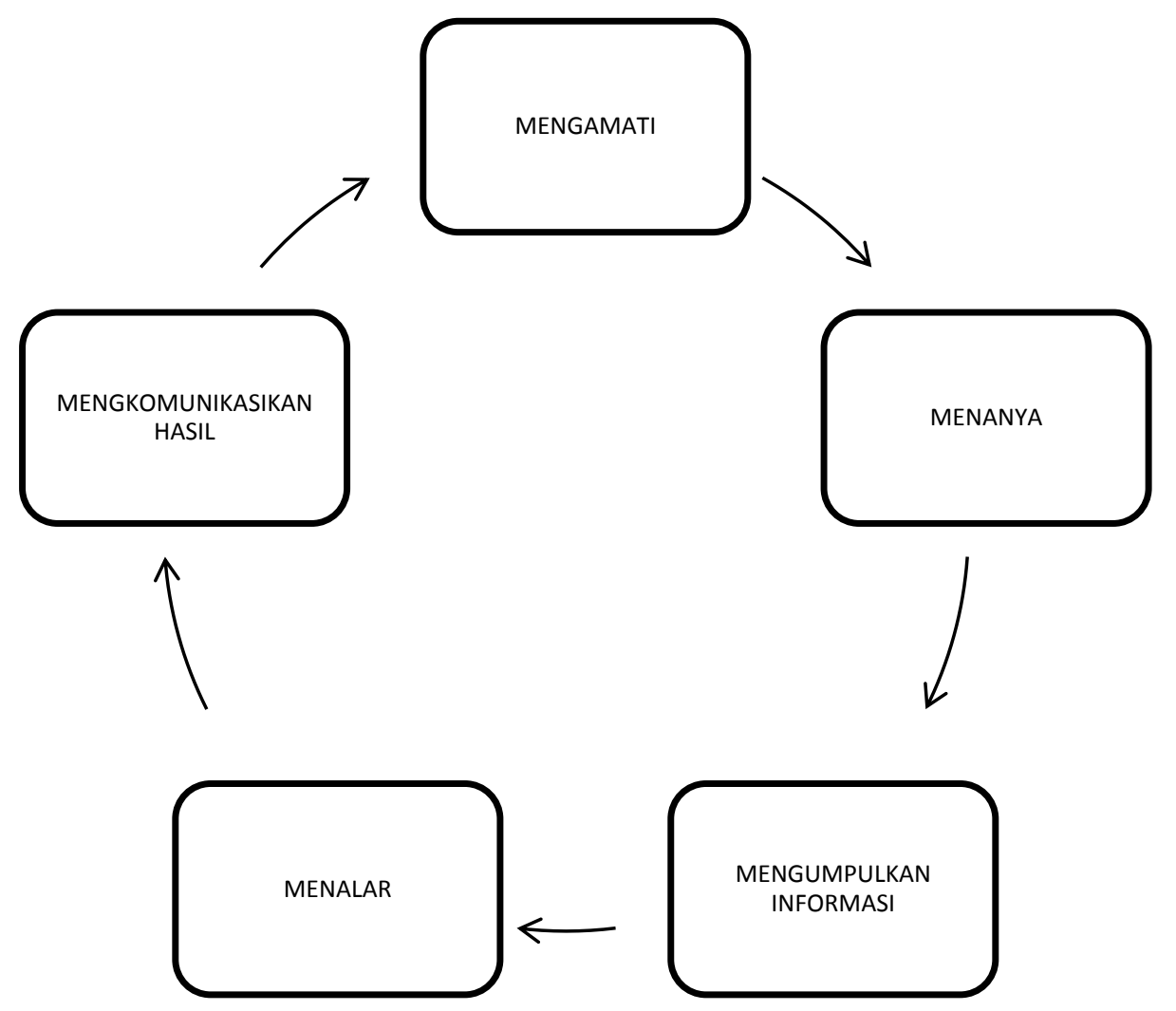

Bagan Pendekatan Saintifik dalam Pembelajaran

(Permendikbud No. 81 A Tahun 2013)

Tiga pengertian di atas membantu merumuskan pemahaman kita terhadap lima proses saintifik (Nurani, 2015) sebagai berikut:

a. Mengamati adalah kegiatan yang mendorong peserta didik untuk menunjukkan keingintahuan, kesungguhan, dan ketelitian ketika mengamati berbagai objek menggunakan berbagai indera, melalui melihat, mendengar, menghidu, merasa, dan meraba.

b. Menanya sebagai salah satu proses mencari tahu atau mengkonfirmasi atau mencocokkan pengetahuan yang sudah dimiliki anak dengan pengetahuan baru yang sedang dipelajarinya. 
c. Mengumpulkan informasi dilakukan melalui eksplorasi seperti: melakukan, mencoba, mendiskusikan, dan menyimpulkan hasil dari berbagai sumber.

d. Menalar merupakan proses lebih lanjut di mana anak mulai menggabungkan pengetahuan yang sudah dimilikinya dengan pengetahuan baru yang didapatkannya sehingga anak mendapatkan pemahaman yang lebih baik tentang suatu hal.

e. Mengkomunikasikan hasil merupakan proses penguatan pengetahuan terhadap pengetahuan baru yang didapatkan anak.

\section{Penilaian Autentik}

Penilaian dilakukan oleh pendidik dengan menggunakan pendekatan otentik(Authentic Assessment). Penilaian Otentik adalah penilaian berhubungan dengan kondisi nyata dan dalam konteks yang bermakna dan dilakukan pada saat anak terlibat dalam kegiatan bermain (tugas) secara mandiri atau bersama anak lain (Kemdikbud, 2014).

Penilaian yang baik hendaknya minimal memenuhi beberapa kriteria sebagai berikut ( Nurani, 2015):

a. Mengandung pemahaman yang penting tentang perkembangan anak,

b. Terhubungkan dengan kurikulum,

c. Sesuai dengan sikap, pengetahuan dan keterampilan yang diukur,

d. Menghargai keberagaman dari kemampuan anak,

e. Tidak menghabiskan waktu.

Perangkat pembelajaran yang sesuai dengan kurikulum yang berlaku akan meningkatkan kualitas pembelajaran yang dilaksanakan di PAUD Gemilang Kembaran. Kualitas pembelajaran ini akan dapat dibuktikan pada saat PAUD Gemilang Kembaran kembali mengajukan akreditasi lima tahun yang akan datang. Akreditasi bagi sebuah lembaga pendidikan adalah 
bukti bahwa pembelajaran yang dilakukan pada lembaga tersebut berkualitas. Workshop perangkat pembelajaran ini bertujuan untuk membenahi kurikulum PAUD Gemilang baik secara administratif maupun teknis agar sesuai dengan kurikulum 2013 PAUD.

Solusi yang dilakukan adalah workshop perangkat pembelajaran yang terdiri dari (1) penyusunan perencanaan pembelajaran dimulai dari program tahunan, program semester, rencana pelaksanaan pembelajaran mingguan, dan rencana pelaksanaan pembelajaran harian, (2) penyusunan materi ajar, (3) pembuatan media pembelajaran dari barang bekas, dan (4) proses penilaian yang terstandar.

1. Penyusunan perencanaan pembelajaran

Pertemuan dilakukan setiap hari Kamis, satu kali dalam satu minggu. Workshop dilaksanakan pada minggu ketiga dan keempat di bulan Oktober 2016. Hari kamis pada minggu ke tiga digunakan untuk menyusun perencanaan pembelajaran kemudian hari Kamis minggu keempat digunakan untuk mempresentasikan dan mengevaluasi perencanaan pembelajaran yang telah dibuat. Program tahunan dan program semester diambil dari program tahunan dan program semester yang telah disusun dalam KKG. Peserta workshop menyusun program mingguan dan program harian berpedoman pada prota dan promes. Hasilnya adalah program mingguan dan program harian TK kelompok A dan kelompok B.

2. Penyusunan materi ajar

Workshop penyusunan materi ajar dilakukan pada hari Kamis minggu pertama dan kedua di bulan November 2016. Perencanaan pembelajaran yang telah tersusun kemudian dilengkapi dengan materi ajar yang dipersiapkan oleh guru. 
3. Pembuatan media dari barang bekas

Pembuatan media disesuaikan dengan perencanaan pembelajaran dan materi ajar yang telah ada. Media dibuat untuk mendukung kegiatan pembelajaran yang telah direncanakan. Workshop lebih menekankan kepada pemanfaatan barang bekas agar TK tidak terbebani dengan biaya pengadaan media, serta meningkatkan kreativitas guru.

4. Proses penilaian terstandar/autentik

Penilaian autentik dilakukan dengan pemberian informasi yang lengkap mengenai penilaian autentik, diskusi berbagai kendala dalam melakukan penilaian autentik, dan praktek melakukan penilaian autentik. Pengkajian terhadap penilaian autentik dilakukan pada hari Kamis minggu ketiga dan keempat bulan November 2016. Penilaian autentik di bahasa mulai dari deskripsi sampai dengan contoh pembuatan penilaian. Pertemuan ini diawali dengan membahas tentang bagaimana melakukan penilaian, yaitu melalui:

a. Mengumpulkan informasi, dilakukan melalui observasi, interview anak, orang tua, anggota keluarga lain, dan guru.

b. Dokumentasi, melalui video, catatan harian, rekaman suara, foto, dan sebagainya.

c. Menganalisa, menggunakan teori-teori untuk menentukan rekaman atau data-data sehingga berkaitan dengan teori.

d. Menerapkan, menggunakan bukti-bukti dari analisa data untuk menginformasikan dan memperbaiki pembelajaran.

Pembahasan berlanjut pada aplikasi penilaian autentik yaitu aplikasi pembuatan catatan anekdot, catatan harian, dan penilaian hasil karya. Diskusi yang berkembang adalah mengapa penilaian itu hendaknya autentik dan apakah yang membedakan dengan penilaian yang sudah 
dilakukan selama ini. Hasil diskusi dalam workshop ini menghasilkan pemikiran sebagai berikut:

a. Pada dasarnya sebuah penilaian adalah proses mengumpulkan dan menafsirkan berbagai informasi secara sistematis, terukur, berkelanjutan, menyeluruh tentang tumbuh kembang yang telah dicapai peserta didik selama kurun waktu tertentu. Berbeda dengan penilaian sebelumnya yang masih didominasi subjektivitas penilai atau guru. Penilaian autentik lebih objektif karena berhubungan dengan kondisi nyata dan dalam konteks yang bermakna dan dilakukan pada saat anak terlibat dalam kegiatan bermain atau tugas secara mandiri atau bersama anak lain.

b. Penilaian yang baik itu minimal memiliki ciri sebagai berikut:

1) Mengandung pemahaman yang penting tentang perkembangan anak;

2) Terhubungkan dengan kurikulum;

3) Sesuai dengan sikap, pengetahuan, dan keterampilan yang diukur;

4) Menghargai keragaman dari kemampuan anak;

5) Tidak menghabiskan waktu.

Diskusi ini kemudian dilanjutkan pada implementasi penilaian autentik yaitu guru melakukan pengumpulan data dan dokumentasi. Beberapa guru yang lebih dulu memahami penilaian autentik membawa contoh catatan anekdot dan catatan harian untuk kemudian secara bersama sama dianalisis dan kemudian dijadikan dasar sebagai penilaian harian sebagai berikut: 


\section{Contoh Catatan Harian}

Nama Anak : Bagas

Tanggal \& Waktu : 1 Agustus 2014 pk 09.10

Tempat : Area Balok

\section{Peristiwa dan Perilaku :}

Rio dan Bagas mulai berdebat tentang siapa yang akan mengemudi truk. Mario berkata, “Tidak ada yang jadi temanku kalau sopirnya bukan aku." Bagas mengusulkan kalau masih ada dua truk lain dan satu pesawat - Mario bisa jadi pilotnya. Dia dan Rio yang akan jadi sopir truknya.

\section{Contoh Catatan Anekdot}

Nama Anak : Melissa

Tanggal \& Waktu : 15 Juli 2014 pk.08:45 WIB

Tempat : Area Membaca

\section{Peristiwa dan Perilaku :}

Melissa duduk di sebelah Tina di dekat meja baca. Tina menyapa Melissa, "Hi, Melissa! Mau baca buku sama aku ?" Melissa berkata bahwa dia tidak bisa membaca. Tina menjawab, “Kita lihat gambarnya saja." 


\begin{tabular}{|c|c|c|c|c|}
\hline \multicolumn{5}{|c|}{ 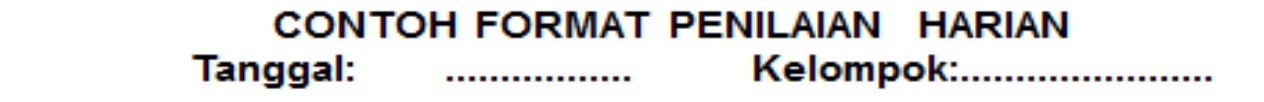 } \\
\hline $\mathrm{KI})$ & KD & Belum Muncul & $\begin{array}{l}\text { Sudah } \\
\text { Muncul }\end{array}$ & Ket. \\
\hline Sikap Spiritual & $\begin{array}{l}\text { Mengenal sebagai cipt } \\
\text { aan Tuhan }\end{array}$ & $\begin{array}{l}\text { Hanin, Bintang, } \\
\text { Ika }\end{array}$ & $\begin{array}{l}\text { Tio, Ade, } \\
\text { Santi, Euis }\end{array}$ & \\
\hline Sikap Sosial & Perilaku sehat. & $\begin{array}{l}\text { Tio, Ade, Santi, } \\
\text { Badu, Sisi, Euis }\end{array}$ & & \\
\hline \multirow[t]{2}{*}{ Pengetahuan } & $\begin{array}{l}\text { Mengenal fungsi } \\
\text { anggota badan dalam } \\
\text { memancing }\end{array}$ & $\begin{array}{l}\text { Tio, Ade, Santi, } \\
\text { Badu, Sisi, Euis }\end{array}$ & $\begin{array}{l}\text { Hanin, } \\
\text { Bintang, Tio }\end{array}$ & \\
\hline & $\begin{array}{l}\text { Memahami konsep } \\
\text { warna, dan ukuran }\end{array}$ & $\begin{array}{l}\text { Ratih, Ida, Budi, } \\
\text { Yuni, Tio, .... }\end{array}$ & & \\
\hline Keterampilan & $\begin{array}{l}\text { Menceritakan } \\
\text { lingkungan hidup ikan }\end{array}$ & $\ldots \ldots$. & & \\
\hline
\end{tabular}

Belum muncul : Jika kompetensi yang di harapkan belum terl ihat

Sudah muncul: Jika kompetensi yang diharapkan sudah terlihat

Setelah guru melakukan analisis di atas dalam pertemuan kedua ini ada tagihan yang dikerjakan oleh guru untuk membuktikan sejauh mana implementasi kurikulum ini dikuasai. Oleh karena itu guru akan mengumpulkan rencana kegiatan harian $(\mathrm{RKH})$ yang sudah menggunakan pendekatan saintifik dalam pembelajarannya dan Rubrik Penilaian yang sudah autentik.

\section{PENUTUP}

PAUD Gemilang merupakan salah satu lembaga PAUD di Kecamatan Kembaran yang senantiasa berusaha mengembangkan dan memajukan kualitas pendidikan yang diselenggarakan. Upaya memajukan kualitas tersebut tidak hanya dari aspek fisik namun juga meningkatkan kualitas penyelenggaraan KBM. Hal ini dibuktikan dengan pengiriman berkas akreditasi yang sudah dilakukan penilaian pada tahun ini dan hasilnya, PAUD Gemilang Kembaran terakreditasi B. 
Penilaian akreditasi bagi PAUD Gemilang Kembaran merupakan sebuah proses untuk meningkatkan pelayanan PAUD kepada peserta didik. Oleh karena itu masukan tim penilai menjadi sangat berharga dan menjadi dasar untuk melakukan pembenahan diri. Pengembangan perangkat pembelajaran merupakan solusi untuk mengatasi kelemahan dalam penilaian tersebut antara lain pada program tahunan, program semester, RPPM, dan RPPH untuk kemudian disesuaikan dengan kurikulum 2013 PAUD.

\section{DAFTAR PUSTAKA}

Ali Nugraha. 2008. Pengembangan Pembelajaran Sains Pada Anak Usia Dini. Bandung: JILSI Foundation.

Direktorat Jendral PAUDNI. 2014. Pedoman Pelatihan Guru untuk Anak Usia 4-6 Tahun Implementasi Kurikulum 2013 PAUD. Jakarta: Kementerian Pendidikan dan Kebudayaan Republik Indonesia.

Oemar Hamalik. 2009. Dasar-dasar Pengembangan Kurikulum. Bandung : PT Remaja Rosdakarya.

Peraturan Menteri Pendidikan dan Kebudayaan Republik Indonesia Nomor 81a Tahun 2013 Tentang Implementasi Kurikulum.

Saylor, J.G., Alexander, W.M., dan A.J. Lewis. 1981.Curriculum Planning for Better Teaching and Learning. New York: Holt Renehart and Winston.

Yuliani Nurani. 2015. Implementasi Kurikulum 2013 PAUD. Jakarta: Yayasan Yebefo. 